\title{
An Experimental Study on the Motion of Floating Bodies Arranged in Series for Wave Power Generation
}

\author{
Seiki Chiba ${ }^{1}$, Kenta Hasegawa ${ }^{2}$, Mikio Waki ${ }^{3}$ and Sho Kurita ${ }^{4}$ \\ 1. Chiba Science Institute, Yakumo, Meguro-Ward, Tokyo 152-0023, Japan \\ 2. National Maritime Research Institute, 6-38-1 Shinkawa, Mitaka-City, Tokyo 181-0004, Japan \\ 3. Wits Inc., Oshiage, Sakura-City, Tochigi 329-1334, Japan \\ 4. Kureha Elastomer Co. Ltd, Kanonnji-cho, Tsu-City, Mie 514-8511, Japan
}

\begin{abstract}
This paper considered the optimal arrangement on the assumption that multiple power generation systems are used in a row ahead of the realization of the wave power generation system using the DE (dielectric elastomer) which is expected to be popularized in the future. A power generation system using DEs was studied as a moored floating body, and tank tests were conducted. There are few studies on the influence of multiple moored floating bodies on each other. Those studies clarified the fluctuation, energy absorption efficiency, tension mooring force and quietness characteristics produced from differences in the arrangement of the floating bodies within the floating body group and so on utilizing the principle of double oscillating water columns. The purpose of this paper is to clarify the influence of floating body intervals and number of floating bodies on floating motion and mooring tension when a plurality of floating bodies are moored in a row perpendicular to the advancing wave direction. We also discuss the conditions of the large power generation system in actual sea areas using the DEs.
\end{abstract}

Key words: Plural floating bodies, motion of floating body, mooring tension, electroactive polymer artificial muscle, dielectric elastomer, generator, marine energy, actuator, Chiba theory.

\section{Introduction}

In recent years, the demand for electric energy has increased all over the world along with the demand for higher standards of living. Power generation methods using renewable energy have attracted much attention against the backdrop of global warming concerns and the dangers of nuclear accidents [1,2]. Marine energy is said to be a reliable source due to its abundance and relatively high energy density when compared to other renewable energy sources such as geothermal, solar, wind and so on. Therefore, power generation systems using wave power and ocean currents are very effective, and a large number of research and development projects have been carried out [3] in this field. The extensive research is necessary partially because conventional generators require high

Corresponding author: Seiki Chiba, Ph.D., professor, research field: dieleastic elastomers. frequency rotation, resulting in increased complexity, size, and cost of the power generation systems.

More recently, the use of DE (dielectric elastomer) in the reverse mode, in which deformation of the elastomer by external mechanical work is used to generate electrical energy, has been gaining more attention (Fig. 1) [4]. DEs are a relatively new transducer technology that was first investigated by R. Pelrine, S. Chiba et al. in 1991 [5]. Since then, a lot of researchers have been studying it [6-15]. Since power generators using DEs do not depend on the frequency, motion and vibration of the low frequency band, which is difficult to utilize for electric power production, they can be easily used [16-19]. SRI International and HYPER DRIVE Co., Ltd. made a buoy type power generation system equipped with a DE power generation device in 2007, and conducted an ocean experiment in order to confirm power generation from natural waves off the coast of Tampa 
Bay in the USA [18]. It was reported that $300 \mathrm{~g}$ of DE was used in the experiment and it was possible to obtain electrical energy of $10 \mathrm{~W}$ at the maximum.

Moretti et al. [20] and Vertechy et al. [21] also showed that one of most promising applications for DE generators was in the field of wave energy harvesting.

Chiba et al. conducted wave tests using experimental models from 2011 to 2015 in order to investigate the power generation characteristics of buoy type power generation systems equipped with DEs and measured the power generation amounts for various wave heights and wave periods [22-26]. The power generation device using the DE has a simple structure and is lightweight, so that it is expected that the wave power generation system can be simplified, lightened and miniaturized. They also considered aggregates of buoys, arrays of buoys with 3 dimensional multi-story DEs, and the spring constant of the DE in order to realize large power generation system in actual sea areas using the DEs [22-28].

The authors considered the optimal arrangement on the assumption that multiple power generation systems are used in a row ahead of the realization of the wave power generation system using the DE which is expected to be popularized in the future. A power generation system using a DE was considered as a moored floating body, and tank tests were conducted. There are few studies on the influence of multiple moored floating bodies on each other, including the research done by Tanaka et al. [29, 30]. They clarified the fluctuation, energy absorption efficiency, tension mooring force and quietness characteristics produced from differences in the arrangement of the floating bodies within the floating body group and so on utilizing the principle of double oscillating water columns.

The purpose of this paper is to clarify the influence of floating body interval and number of floating bodies on floating motion and mooring tension when a plurality of floating bodies are moored in a row perpendicular to the advancing wave direction. We also discuss the conditions of the large power generation system in actual sea areas using the DEs.

\section{Operating Principle of DE Generator}

There are several ways in which DEs can be used to produce electrical energy from the mechanical work used to stretch and contract it. Here we present one such method based on a constant voltage cycle.

Application of mechanical energy to stretch the DE causes a reduction in thickness and expansion of the surface area (see Fig. 1a). At this moment, a voltage may be placed upon the polymer (i.e. positive charges are placed on one side and negative charges on the other side). When the stretching forces are removed, the elastic recovery force of the DE acts to restore the original thickness and to decrease the surface area (see Fig. 1b). The increase in thickness upon relaxation acts to push the opposite charges apart from each other, effectively raising the voltage applied to the DE. Even though the capacitance of the DE reduces upon relaxation, there is a net increase in the energy stored on the DE compared to that put on by the original application of the voltage. This increase can be harvested as electrical energy.

The higher voltage can be measured and compared with predictions based on this DE theory developed by Chiba et al. [19]. In general, experimental data based

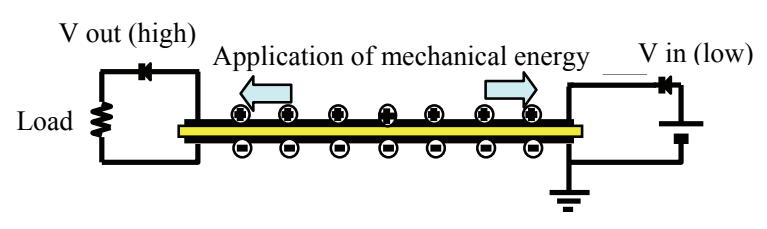

(a) DE STRETCHED

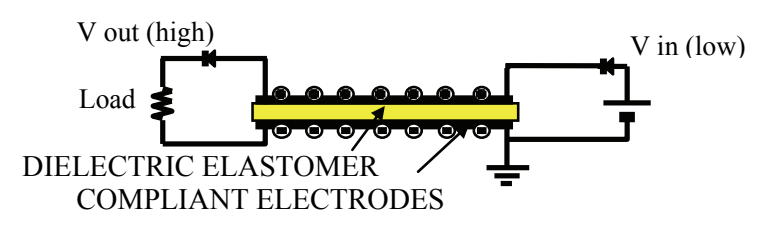

(b) DE RELAXED

Fig. 1 Operating principle of DE power generation [24]. 
on high impedance measurements are in excellent agreement with this prediction.

\section{Experiment Outline}

\subsection{Experimental Equipment}

The floating body used in this experiment is shown in Fig. 2. A rectangular parallelepiped urethane (990 $\mathrm{mm} \times 250 \mathrm{~mm} \times 80 \mathrm{~mm}$ ) was used as a floating body, which was fitted with points for observing movement. Floating motion was measured by tracking the points with a CCD camera and measuring the amount of movement (PERCEPT SCOPE S3160, Hamamatsu Photonics). The floating body moves with three degrees of freedom of heave, surge and pitch by guides set at the four corners for restricting the motion.

Fig. 3 shows the layout of the floating body and the test equipment. The test tank used in this experiment has $15 \mathrm{~m}$ in length, $1 \mathrm{~m}$ in width and $1.4 \mathrm{~m}$ in water depth, and experimental floating bodies were moored near the center. The mooring wire was connected to the ring gauge via a pulley installed below the floating body, so that the tension acting on the mooring wire was measured. Two wave height meters (servo-needle type wave height meter, DENSHI KOGYO Co., Ltd.) were installed between the floating bodies and the wave generator and between the floating bodies and the wave absorbing plate to measure wave height of incident wave and transmitted wave.

\subsection{Test Conditions}

In this experiment, when multiple floating bodies are arranged in a row in the incident direction of a wave, the influence of the distance and number of the floating body on the floating motion and the mooring tension are clarified. Therefore, using four experimental floating bodies at the maximum, four kinds of conditions were set according to the floating body interval and the number of floating bodies. For the sake of simplicity, the floating bodies are named A, B, C from the wave generator side, and the four test conditions are called Cases 1-4 respectively. Experiments were also conducted by varying the wave period and wave height under each test condition. In addition, each floating body was moored with an initial tension of $14.7 \mathrm{~N}$. Table 1 summarizes the test conditions.

\section{Results and Discussion}

In this study, by providing guides to the floating bodies, the floating bodies were restricted so as to move with three degrees of freedom of heave $z$, surge $x$ and pitch $\theta$ (Fig. 4a). In evaluating each floating motion and mooring tension, each value is non-dimensionalized by using absolute wave height $\zeta$, wave number $k$, fluid density $\rho$ and so on. The wave number $k$ is defined as:

$$
k=\frac{2 \pi}{\lambda}
$$

where $\lambda$ is the wave length, which can be calculated by Eq. (2),

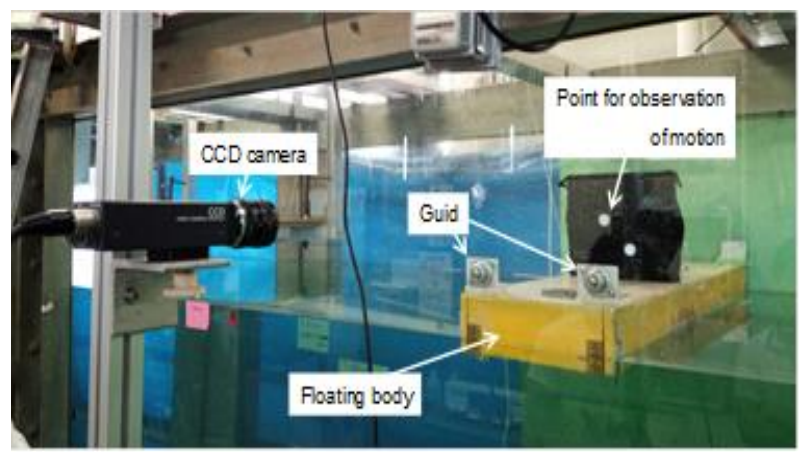

Fig. 2 Experimental floating body.

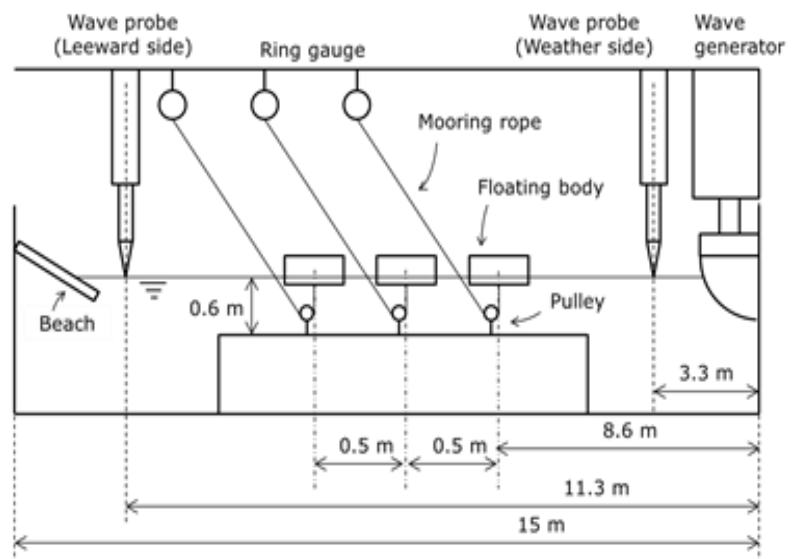

Fig. 3 Experimental facility. 
Table 1 Test conditions.

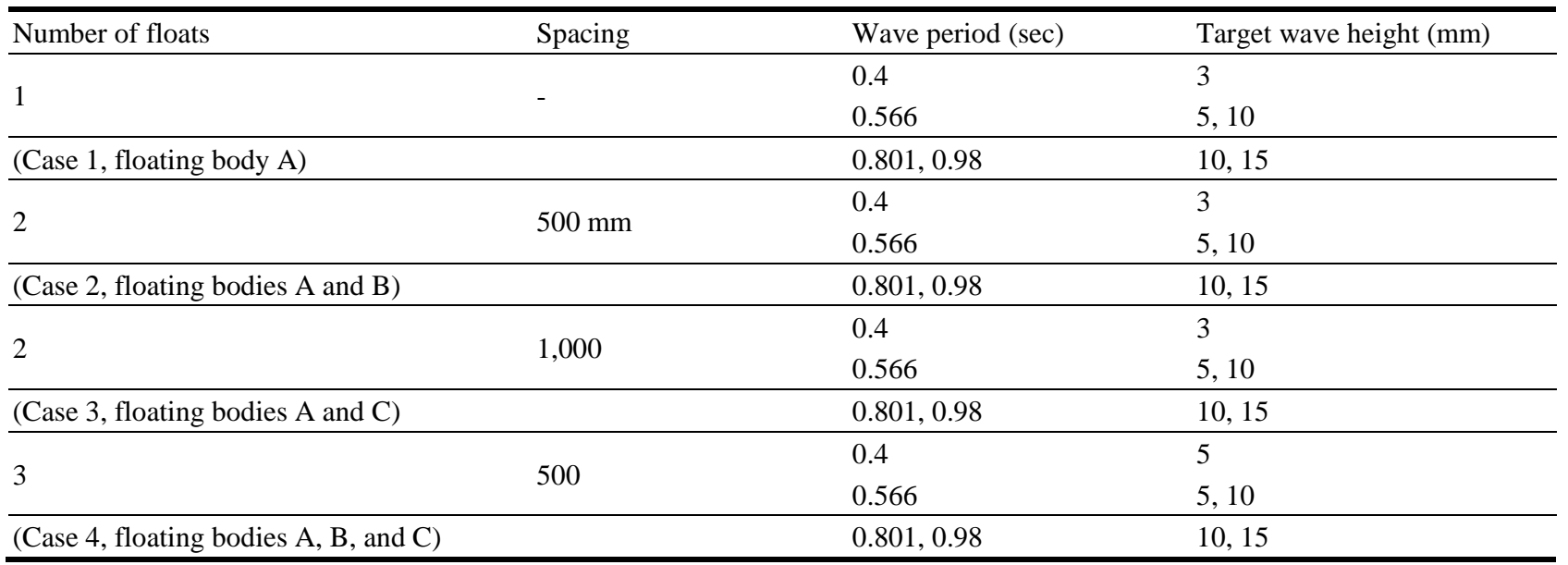

$$
\lambda \approx \frac{g T^{2}}{2 \pi} \tanh \left\{2 \pi \sqrt{\frac{h}{g T^{2}}}\left(1+\sqrt{\frac{h}{g T^{2}}}\right)\right\}
$$

where $h$ and $T$ are the water depth and the wave period, respectively.

Fig. 4b shows the frequency response in Case 1 with only one floating body. The vertical axis indicates each non-dimensionalized floating motion and mooring tension, and the horizontal axis indicates the wave period. The plots of the figure show the experimentally obtained values and they are connected by a smooth curve. As shown in Fig. 4b, both the heave and the pitch are almost leveled, and the surge becomes small near the wave period of $0.6 \mathrm{sec}$. The tension slightly increases in proportion to the wave period.

Next, the experimental results of two floating bodies of Case 2 (floating bodies $\mathrm{A}$ and $\mathrm{B}$ ) at an interval of $500 \mathrm{~mm}$ are shown in Fig. 5. Fig. 5a shows the frequency response of the floating body $\mathrm{A}$ on the wave generator side, that is, the floating body A where the wave produced by the wave generator first collides. The heave has a nearly constant value regardless of the wave period, and the surge decreases around the wave period of $0.6 \mathrm{sec}$. The pitch increases in proportion to the wave period, and the tension falls at the wave period of $0.8 \mathrm{sec}$. Fig. $5 \mathrm{~b}$ shows the frequency response of the floating body $\mathrm{B}$, and the motion of the floating body $\mathrm{B}$ is caused by the wave passing through the floating body A. Here, the heave and the pitch both increase gradually in proportion to

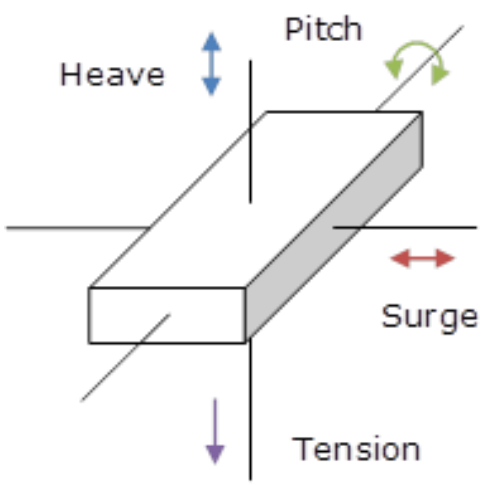

Fig. 4a Motion direction of floating body.

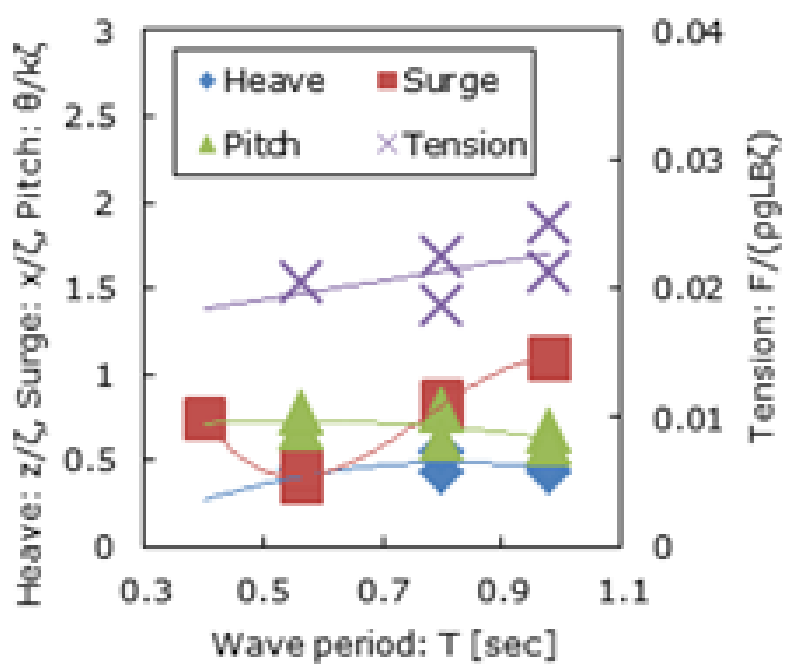

Fig. 4b The RAO (response amplitude operator) of floating body A for case1. 


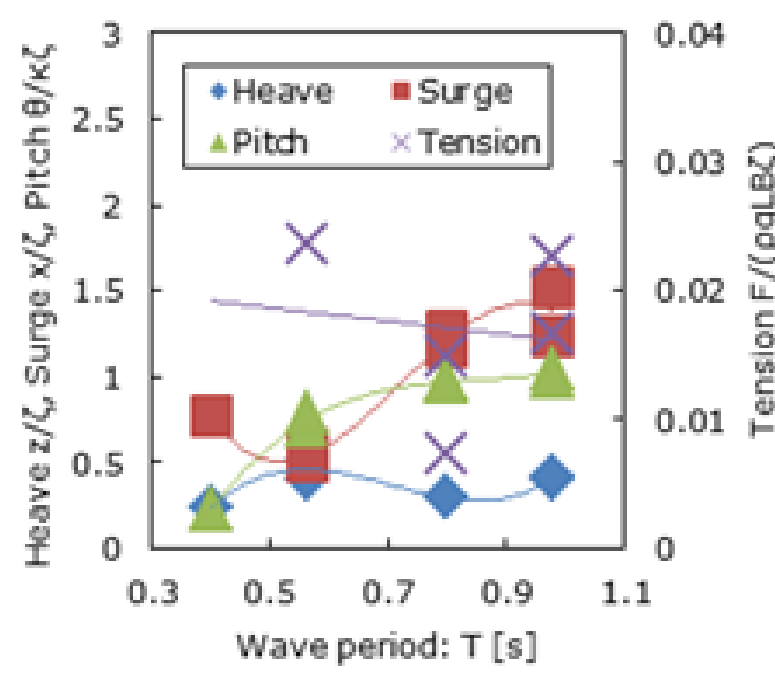

(a) Floating body A

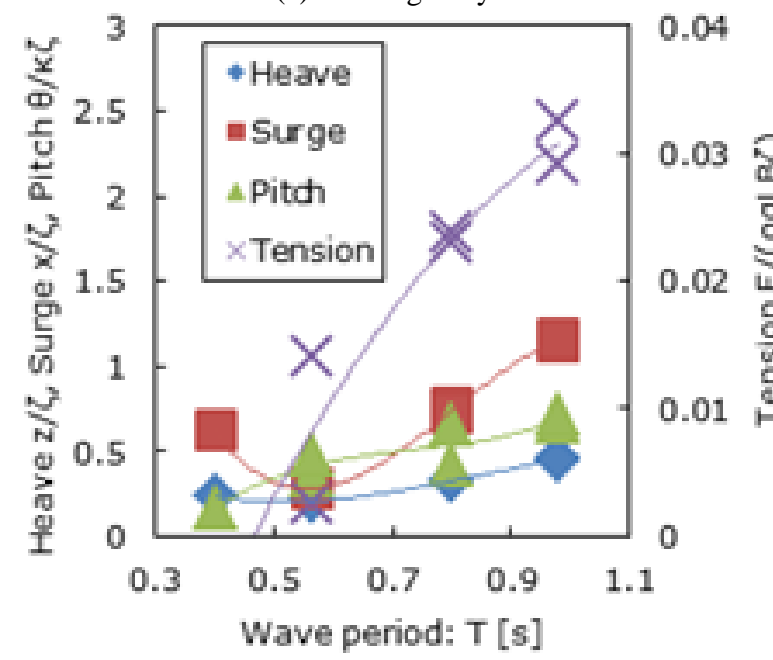

(b) Floating body B

Fig. 5 The RAO for Case 2.

the wave period, whereas the mooring tension increases greatly. The surge decreases around the wave period of $0.6 \mathrm{sec}$. When comparing the floating bodies $\mathrm{A}$ and $\mathrm{B}$, the floating body $\mathrm{B}$ has a smaller value overall than the floating body $\mathrm{A}$ with respect to the floating body motion. Regarding the mooring tension, however, the floating body $\mathrm{B}$ has a larger value in the range of the wave period of $0.8 \mathrm{sec}$ or more.

Fig. 6 shows the results for Case 3, two floating bodies (floating bodies $\mathrm{A}$ and $\mathrm{C}$ ) and a floating body interval of $1,000 \mathrm{~mm}$. For the floating body $\mathrm{A}$, the heave shows a nearly constant value, whereas the surge and pitch become peaks around the wave period of 0.8 and $0.6 \mathrm{sec}$, respectively, and the mooring tension falls in the wave period of $0.8 \mathrm{sec}$ (Fig. 6a). As for the floating body $\mathrm{C}$, each value monotonically increases in proportion to the wave period (Fig. 6b). However, we could not get the heave data in this condition due to the occurrence of considerable noise. When comparing the floating bodies $\mathrm{A}$ and $\mathrm{C}$, it can be seen that the floating body $\mathrm{C}$ moves significantly at the wave period of $1.0 \mathrm{sec}$.

Finally, the experimental results of three floating bodies of Case 4 (floating bodies A, B and C) at an interval of $500 \mathrm{~mm}$ are shown in Fig. 7. For the floating body A shown in Fig. 7a, the heave and the mooring tension become smaller, and the surge and

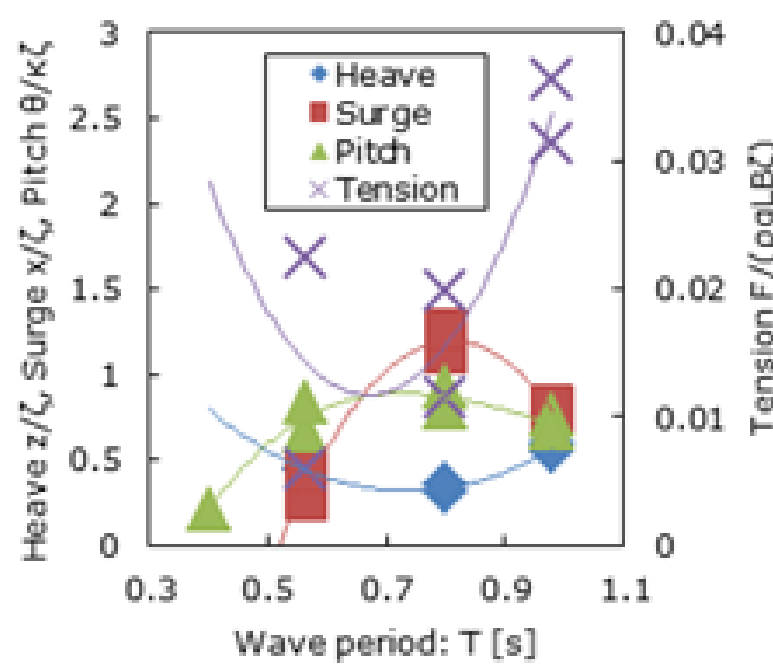

(a) Floating body $\mathrm{A}$

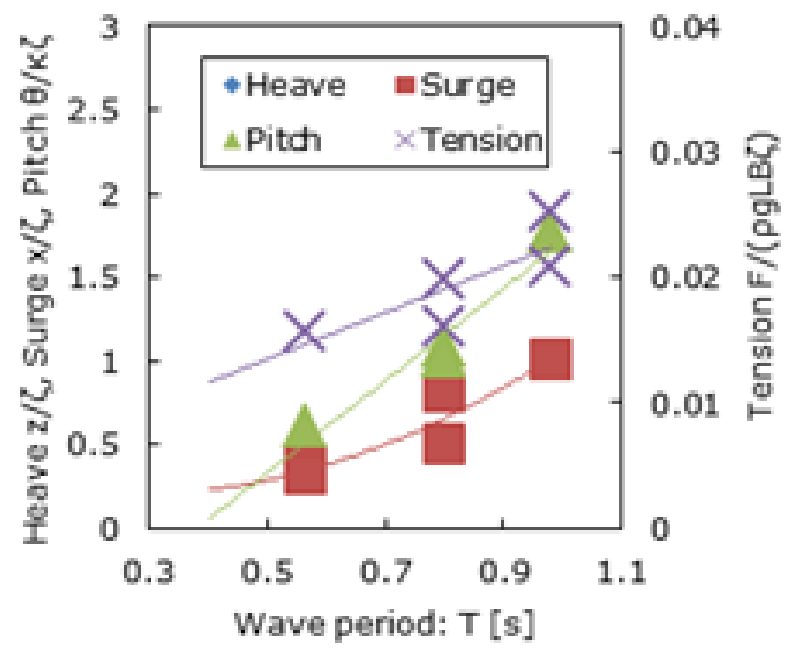

(b) Floating body $\mathrm{C}$

Fig. 6 The RAO for Case 3. 
the pitch are larger at the wave period of $0.8 \mathrm{sec}$. Each value of the floating body B increases in proportion to the wave period (Fig. 7b). Regarding the floating body $\mathrm{C}$, the heave and the surge do not change very much, and the pitch and the tension increase remarkably as the wave period increases (Fig. 7c). Comparing the three floating bodies, the pitch and the tension of the floating body $\mathrm{C}$ become larger than the other floating bodies at a wave period of $1.0 \mathrm{sec}$.

Based on the frequency response of the floating body $\mathrm{A}$ under Case 1 (Fig. 4b), the frequency response of the floating body $\mathrm{A}$ in each case (Figs. 5a-7a) is compared. Focusing on the floating body A of Case 1 and 2 , although there is not much change in the heave, Case 2 has a lager value with respect to the surge and the pitch in the wave period of $0.7 \mathrm{sec}$ or more. The mooring tension falls remarkably at around the wave period of $0.8 \mathrm{sec}$ in Case 2 (Figs. 4b and 5a). It is characteristic that the surge increases at the wave period of $0.8 \mathrm{sec}$ and decreases at $1.0 \mathrm{sec}$ in comparison between Cases 1 and 3. On the other hand, the mooring tension decreases at the wave period of $0.8 \mathrm{sec}$ and increases at $1.0 \mathrm{sec}$ (Figs. $4 \mathrm{~b}$ and 6a). When comparing Case 1 and 4, remarkable changes are observed in surge, pitch and mooring tension at a wave period of $0.8 \mathrm{sec}$ (Figs. $4 \mathrm{~b}$ and 7a).

From the above results, the floating body A shows a constant value irrespective of the number of floating bodies and floating body intervals in a range where the wave period is smaller than about $0.6 \mathrm{sec}$, and the floating bodies $\mathrm{B}$ and $\mathrm{C}$ experience less motion. This is presumably because the waves reflect without passing through the floating body as the wave period decreases. When the wave period is around $0.8 \mathrm{sec}$, the influence of the floating bodies $\mathrm{B}$ and $\mathrm{C}$ on the floating body A becomes larger, and a significant change is caused in the values of parameters other than the heave. Particularly in the case of three floating bodies, it can be confirmed that the increase and decrease of the values are greater than in the case

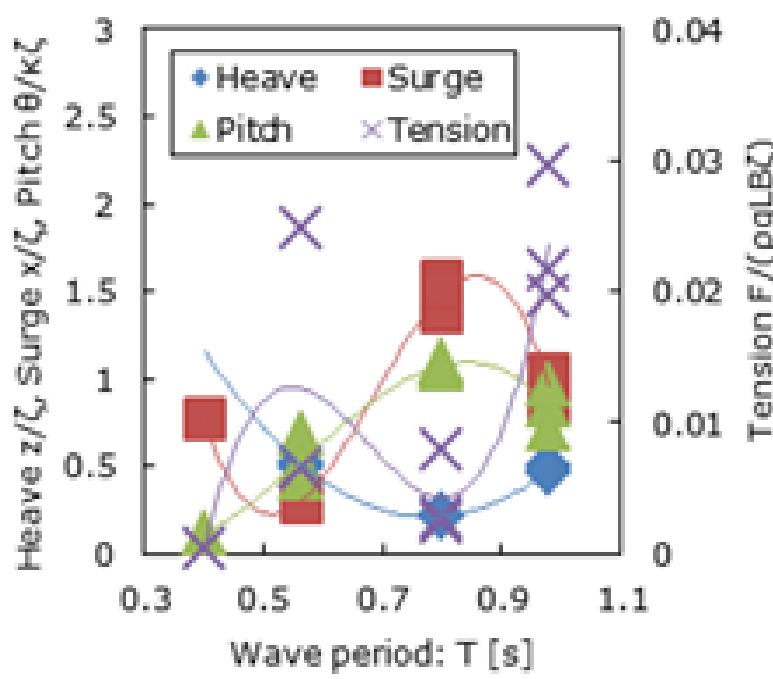

(a) Floating body A

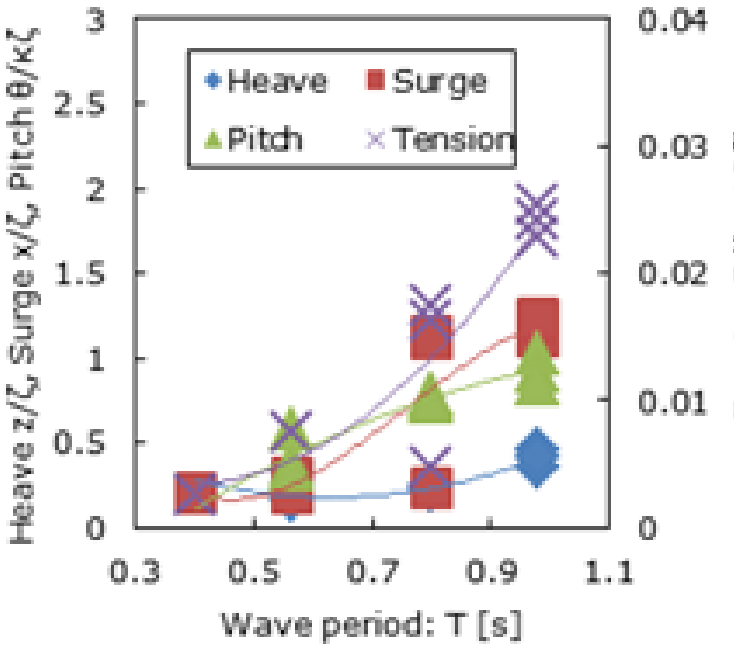

(b) Floating body B

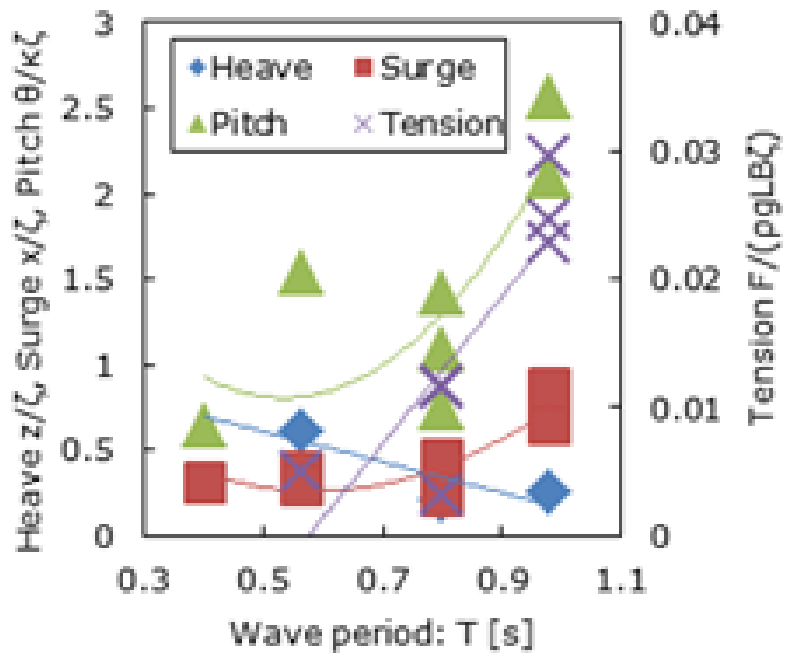

(c) Floating body $\mathrm{C}$

Fig. 7 The RAO for Case 4. 
of 2 floating bodies, and the influence on the floating body $\mathrm{A}$ in the case of two floating bodies is not changed by the floating body interval. For the wave period of around $1.0 \mathrm{sec}$, the surge and the pitch of the floating body A increase under the condition of two floating bodies arranged by the short interval of 500 $\mathrm{mm}$, and an increase in mooring tension at the floating body $\mathrm{A}$ is observed under the condition of two floating bodies arranged by the long interval of 1,000 $\mathrm{mm}$. Furthermore, an increase in the pitch at the floating body $\mathrm{C}$ is noticeable.

\section{Large Power Generation System in Real Sea Area Using DEs}

We found in this experiment that most of the wave is reflected by the collision with the foremost floating body - in the range where the wave period is smaller than about $0.6 \mathrm{sec}$. As the result, it does not reach the floating body behind it and the influence of the multiple floating bodies remains minimal.

However, in the vicinity of $0.8 \mathrm{sec}$, the influence of multiple floating bodies is large.

When the period of the wave is around $1.0 \mathrm{sec}$, narrow spacing between the floats leads to an increase in the surge and pitch, and an increase in the floating body interval causes an increase in mooring tension.

From these experimental results, when used in a real sea area, it is necessary to properly obtain the interval between the buoys in order to obtain the maximum generating power from the waves.

In order to realize a large power generation system in which many buoys are arranged in actual sea areas, in addition to the above findings, the following three points proposed by Chiba etal. are also important:

(1) To set the spring constant of the DE to match the waves typically occurring in the sea area where the buoy equipped with $\mathrm{DE}$ is to be installed [24, 26].

(2) The aggregate of buoys should be arranged so that it can receive waves in all directions occurring in that area.

(3) If possible, arrange buoys with 3 dimensional multi-story DEs [27, 28].

Of course, each buoy shape is important. It should be designed as the optimum floating body suitable for the waves in that area $[24,26]$. By making good use of the above techniques, larger power can be realized with high efficiency in actual sea areas through successful matching.

\section{Conclusion}

In this experiment, water tank tests were conducted focusing on floating motion and mooring tension with regard to the influence of floating body intervals and number of floating bodies when mooring two or three floating bodies in a row lined perpendicular to the advancing wave direction.

In the range where the wave period is smaller than about $0.6 \mathrm{sec}$, most of the wave is reflected by the collision with the foremost floating body, so that it does not reach the rear floating bodies and the influence of the multiple floating bodies remains small. When the wave period is around $0.8 \mathrm{sec}$, the influence of multiple floating bodies becomes large, especially an increase in surge and pitch, and a decrease in mooring tension are noticeable in the floating body which first collides with the wave. At this time, although the influence of differences in floating body intervals is small, the influence becomes larger as the number of floating bodies increases. For the wave period of around $1.0 \mathrm{sec}$, it is revealed that if the interval of the floating bodies is narrow, the surge and the pitch of the floating body which first collides with the wave increase, and if the interval is wide, it causes an increase of the mooring tension.

In order to realize a large power generation system in real sea areas using DEs, it is necessary to properly obtain the interval between the buoys in order to obtain the maximum generating power from the waves generated in the sea area.

In addition to the above findings, the following four points are also important:

(1) To set the shape of DE that matches the waves 
typically occurring in the sea area where the buoy equipped with DE is to be installed [24, 26].

(2) If possible, arrange buoys with multi-story DEs in 3 dimensions [27, 28].

(3) Each buoy shape should be designed as the optimum floating body suitable for the waves in that area $[24,26]$.

(4) The aggregate of buoys should be arranged so that it can receive waves in all directions occurring in that area.

\section{Acknowledgement}

The part of this research was financially supported by the Sasakawa Scientific Research Grant from The Japan Science Society.

\section{References}

[1] Renewable Energy Policy Network for the 21st Century: Renewables 2012 Global Status Report. 2012. Paris, REN21 Secretariat.

[2] Renewable Energy Policy Network for the 21st Century: Renewables Global Futures Report. 2013. Paris, REN21 Secretariat.

[3] U.S. Department of Energy: Ocean Energy Technology Overview. 2009. Federal Energy Management Program.

[4] Chiba, S. 2002. "MEMS and NEMS Applications of Dielectric Elastomer and Future Trends." Electronic Packaging Technology (1): 32-8.

[5] Pelrine, R., and Chiba. S. 1992. "Review of Artificial Muscle Approaches." Proc. of Third International Symposium on Micro-machine and Human Science (Invited), Nagoya, Japan, 1-9.

[6] Pelrine, R., Kornbluh, R., Pei, Q., Joseph, J., and Chiba. S. 2000. "High-Field Deformation of Elastomeric Dielectrics for Actuators." Mater Sci. Eng. C11: 89-100.

[7] Koh, S. J. A., Zhao, X., and Suo, Z. 2009. "Maximal Energy That Can Be Converted by a Dielectric Elastomer Generator." Applied Physics Letters 94 (26): 262902-3.

[8] Huang, J., Shian, S., Suo, Z., and Clarke, D. 2013. "Maximizing the Energy Density of Dielectric Elastomer Generators Using Equi-Biaxial Loading." Advanced Functional Materials 23: 5056-61.

[9] Kaltseis, R., Keplinger, C., Baumgartner, R., Kaltenbrunner, M., Li, T., Mächler, P., Schwödiauer, R., Suo, Z., and Bauer, B. 2011. "Method for Measuring Enegy Generation and Efficiency of Dielectric Elastomer Generators." Appl. Phys. Lett. 99: 162904. doi.org:10.1063/1.3653239.
[10] Brouchu, P. A., Li, H., Niu, X., and Pei, Q. 2010. "Factors Influencing the Performance of Dielectric Elastomer Energy Harvesters." In Proc. SPIE 7642 (1): 76422J.

[11] Vertechy, R., Papini Rosati, G. P., and Fontana, M. 2015. "Reduced Model and Application of Inflating Circular Diaphragm Dielectric Elastomer Generators for Wave Energy Harvesting." Journal of Vibration and Acoustics, Transactions of the ASME 137: 11-6.

[12] Bortot, E., and Gei, M. 2015. "Harvesting Energy with Load-Driven Dielectric Elastomer Annular Membranes Deforming Out-of-Plane." Extreme Mech. Lett. 5: 62-73.

[13] Moretti, G., Fontana, M., and Vertechy, R. 2015. "Parallelogram-Shaped Dielectric Elastomer Generators: Analytical Model and Experimental Validation." Journal of Intelligent Material Systems and Structures 26 (6): 740-51.

[14] Brochu, P., Yuan, W., Zhang, H., and Pei, Q. 2009. "Dielectric Elastomers for Direct Wind-to-Electricity Power Generation." In Proc. of ASME 2009 Conference on Smart Materials, Adaptive Structures and Intelligent System.

[15] Zhou, J., Jiang, L., and Khayat, R. 2016. "Dynamic Analysis of a Tunable Viscoelastic Dielectric Elastomer Oscillator under External Excitation." Smart Materials and Structures 25 (2): 025005.

[16] Chiba, S., Pelrine, R., Kornbluh, R., Prahad, H., Stanford, S., and Ecckele, J. 2007. "New Opportunities in Electric Generation Using Electroactive Polymer Artificial Muscle (EPAM).” J. Jpn. Inst. Energy 86: 743-7.

[17] Chiba, S., Waki, M., Kornbluh, R., and Pelrine, R. 2007. "Extending Applications of Dielectric Elastomer Artificial Muscle." Proceedings of SPIE 6524: 652424-1-5. San Diego, CA.

[18] Chiba, S., Kornbluh, R., Pelrine, R., and Waki, M. 2008. "Innovative Power Generation for Energy Harvesting Using Electroactive Polymer Artificial Muscles." Proceedings of SPIE 6927: 692715-1-9. San Diego, CA.

[19] Chiba, S., Waki, M., Wada, T., Hirakawa, Y., Masuda, K., and Ikoma, T. 2013. "Consistent Ocean Wave Energy Harvesting Using Electroactive Polymer (Dielectric Elastomer) Artificial Muscle Generators.” Applied Energy 104: 495-502.

[20] Moretti, G., et al. 2014. "Modeling of an Oscillating Wave Surge Converter with Dielectric Elastomer Power Take-off (2014)." Proc. Offshore Mechanics and Arctic Engineering-OMAE, 9A.

[21] Vertechy, R., et al. 2014. "In-tank Tests of a Dielectric Elastomer Generator for Wave Energy Harvesting." Proceedings of SPIE-The International Society for Optical Engineering, 9056.

[22] Chiba, S., Waki, M., Fujita, K., Masuda, K., and Ikoma. 
T. 2017. "Simple and Robust Direct Drive Water Power Generation System Using Dielectric Elastomers.” Journal of Material Science and Engineering B7 2017 (1-2): 39-47. doi:10.17265/2161-6213/2017.1-2.005.

[23] Chiba, S., et al. 2016. "Elastomer Transducers." Advances in Science and Technology (Trans Tech Publications) 97: 61-74. ISSN: 1662-0356.

[24] Waki, M., Chiba, S., et al. 2017. "Development of Wave Generation Module for Small Ships Using Dielectric Elastomer." Journal of Material Science and Engineering B7 (7-8): 171-7. DOI: 10.17265/2161-6221/2017.7-8.007.

[25] Chiba, S., Hasegawa, K., Waki, M., Fujita, K., Ohyama, K., and Shijie. 2017. "Innovative Elastomer Transducer Driven by Karman Vortices in Water Flow." Journal of Material Science and Engineering A 7 (5-6): 121-35. doi:10.17265/2161-6213/2017.5-6.002.

[26] Waki, M., Chiba, S., Song, Z., Ohyama, K., and Shijie, Z. 2017. "Experimental Investigation on the Power Generation Performance of Dielectric Elastomer Water Power Generation mounted on a Square Type Floating Body."
Journal of Material Science and Engineering $A \& B$.

[27] Chiba, S., Waki, M., Masuda, K., Ikoma, T., Osawa, H., and Suwa, Y. 2011. "Innovative Wave Power Generator Using Dielectric Elastomers Artificial Muscle.” Proc. of World Hydrogen Technologies Convention-2011, Scotland, Sept. 2011.

[28] Chiba, S., Waki, M., Masuda, K., Ikoma, T., Osawa, H., and Suwa, Y. 2012. Innovative Power Generation System for Harvesting Wave Energy, Design for Innovative Value towards a Sustainable Society. Netherlands: Springer, 1002-7, ISBN 978-94-007-3010-6.

[29] Tanaka, Y., Motoyoshi, Y., Furukawa, K., and Nakamura, T. 1989. "Theory and Experiment on Wave Power Generators Using a Series of Tightly Moored Floating Bodies." Proceedings of Coastal Engineering, Japan Society of Civil Engineers 36: 769-73.

[30] Tanaka, T., Furukawa, K., and Motoyoshi, Y. 1993. "Research on Wave Power Generation System by Using a Tension Mooring Floating Body." Proceedings of Coastal Engineering, Japan Society of Civil Engineers, 40: 911-5. 